\title{
A systematic review and meta-analysis of the prevalence, trends and spatiotemporal distribution of HIV/AIDS infection in Northern African countries.
}

Mohamed A Daw ( $\square$ mohamedadaw@gmail.com )

University of Tripoli https://orcid.org/0000-0003-1312-5956

Nadia E.M. Sifennasr

University of Tripoli

Abdallah El-Bouzedi

University of Tripoli

Mohamed 0 Ahmed

University of Tripoli

\section{Systematic Review}

Keywords: North Africa, HIV- epidemiology , Meta-analysis, spatial distribution

Posted Date: August 31st, 2020

DOI: https://doi.org/10.21203/rs.3.rs-67533/v1

License: (c) (i) This work is licensed under a Creative Commons Attribution 4.0 International License. Read Full License 


\section{Abstract}

Background: Human immune deficiency virus (HIV) infection is a major global public health concern. Northern African countries carry a disproportionate burden of HIV, accounting for one of the highest prevalences in Africa. Here in, we sought to analyze the epidemiological characterization and spatial trends of HIV infection in the Northern African region.

Methods: A systematic review was carried out on all the published data regarding HIV/AIDS in Northern African countries over a ten year period (2008-2017) following the PRISMA guidelines. We performed a comprehensive literature search using Medline PubMed, Embase, regional and international databases, and country-level reports were searched with no language restriction. The quality, quantity, and geographic coverage of the data were assessed at both the country and region levels. We used randomeffects methods, spatial variables and stratified results by demographic factors. Only original data for the prevalence of HIV infection were included and independently evaluated by professional epidemiologists.

Results: A total of 721 records were identified by our data search, and only 41 that met our criteria were included in the meta-analysis during the study period. There was a considerable variability in the prevalence estimates of HIV within the countries of the region. The overall prevalence of HIV in northern African countries ranged from $0.9 \%(95 \% \mathrm{Cl}(0.8-1.27)$ to $3.8 \%(95 \% \mathrm{Cl}(1.17-6.53))$. The highest prevalence was associated with vulnerable groups, particularly drug abusers and sexual promiscuity. Dense HIV clustering was also reported during the study period, varying from one country to another. At least 13 HIV subtypes and recombinant forms were prevalent in the region. Subtype B was the most common variant, followed by CRF02_AG.

Conclusion: This comprehensive review indicated that HIV infection in Northern African countries is an emerging threat. Effective strategies are needed both at national and regional levels to improve monitoring and controlling the transmission of HIV with a particular emphasis on geographic variability and HIV clustering.

\section{Introduction}

Human immunodeficiency virus (HIV) is one of the most important viruses that has led to several demographic, economic social and even political consequences. Since its discovery in 1980s, HIV/AIDS remains an important public health concern worldwide. Its prevalence has rapidly increased particularly among developing countries[1,2]. As of 2012, over 70 million people have become infected, with HIV of which over 35 million have died. Africa has been the most severely affected geographical area, containing over $70 \%$ of the people living with HIV[3,4]. 
A variety of factors have immensely contributed to the spread of HIV/AIDS. Such factors vary considerably form one region to another and even within the districts of the same region. Recent reports indicated that homosexuality (MSM) has become the dominant mode of transmission among newly diagnosed HIV infections in North America East, Southeast, and South Asia, as well as in Latin America [5-7].

Northern Africa is a vast unique geographical region composed over $30 \%$ of African continent with the longest coast expanding from the Atlantic Ocean to the Mediterranean basin facing the Southern European union[8]. The region has experienced major political and demographic challenges particularly in this decade after the Arab spring. This was complicated with wars, lack of security, major population displacement, weakening of public health systems and Influx of immigrants particularly from West and Sub-Saharan Africa [9-11].

The incidence of HIV has been increasing more rapidly in Northern Africa than in any other global region and AIDS-related mortality has almost doubled in the past decade. Comparable by West and Central African regions HIV transmission rates in the region rose by over $10 \%$ during this decade; with the greatest growth in HIV morbidity and Mortality. This has HIV in this region has been confronted by ignorance and polemic thinking even among health professionals [12.13]. To often, patients living with HIV revealed facing denial of care, stigmatising attitudes, discrimination, and breaches of confidentiality [14].

Furthermore, HIV infection was not well addressed as a public-health challenge in the region and the hidden pandemic is believed to be driven by risky behaviors ( such as sexual and drug-related factors) that are not well indulged in the society. The epidemiology of HIV in the region remains poorly defined. This was complicated by the lack of accurate surveillance data and even the existing data are prone to underestimation biases and do not portray the real picture of new HIV infections in the region [15].

Few studies have been conducted on the prevalence of HIV and its associated factors in Northern Africa. The available studies present inconclusive findings in the prevalence of HIV and its associated factors[16]. Therefore, this systematic review was conducted to assess the prevalence and factors associated with HIV in the region using available published evidence. The findings of this review would be useful to design proper strategies to reduce the prevalence rate of HIV and implement efficient programs of combat the consequence of such infection. 


\section{Methods}

\section{Data Source and Search Strategy}

A systematic internet data search using PubMed, Medline, Google scholar and Embase was performed to identify papers that dealt with the HIV in Northern Africa within ten years period ( from January ${ }^{1 s t}$, 2008 to December $31^{1 \text { st }}$, 2017) without language restriction using specific medical terms to identify papers that dealt with the HIV in Northern Africa including HIV" or AIDS", OR "human immunodeficiency virus" OR "acquired immunodeficiency syndrome") Prevalence, incidence", in Northern Africa", and in each single country within the region. The data search was restricted to the geographical region of Northern Africa encompassing countries that share historical, sociocultural, linguistic, and religious characteristics, and thus covered all seven countries, viz. Egypt, Libya, Tunisia, Algeria, Morocco, Mauritania and Sudan. The geographical location and population of the countries included in the region are shown in supplement 1 . Reports from WHO (world health organization www.who.net) were also identified, reviewed and analyzed to identify the burden of HIV infection in Northern Africa. To minimize publication bias, we retrieved the reference lists and manually searched for relevant studies that met our inclusion criteria in addition to regional and country-level scientific databases. The PRISMA (Preferred Reporting Items for Systematic Reviews and Meta-Analyses) guidelines for this systematic review and used meta-analysis were restrictedly followed to aggregate the data[17,18].

\section{Inclusion and Exclusion Criteria}

Studies of any design that measured the prevalence or incidence of HIV in Northern African countries were included. The Inclusion criteria were based on whether the study provided sufficient information on the prevalence, incidence, demographic and risk factors characteristics. Studies were accepted if descriptions of HIV testing methods were included such as laboratory derived HIV status using biological specimens and on primary data from population in Northern Africa countries. These include Algeria, Egypt, Libya, Mauritania, Morocco, Sudan and Tunisia. The samples had to have a minimum sample size of 25 to be included, detailed descriptions of the sampling, HIV testing, and analytical methods were needed, with sources including peer-reviewed journals and non-peer reviewed publications meeting other criteria and available online in the public domain. Duplications were identified by comparing detailed study characteristics, including author names, study period, study location, the number of infection cases, and the sample size. If two publications were found to be from the same data source, only the earlier publication was included. The exclusion criteria encompassed case reports, case series, editorials, letters to editors, commentaries, literature reviews, and studies reporting HIV prevalence based on self-reporting. studies on HIV status rather than biological testing. Studies not reporting the study period/time and geographical location were also excluded.

\section{Data Abstraction and Quality Assessment}

The titles and abstracts of all records retrieved were screened for relevance independently and were categorized according to quality of study design and methods. The information extracted from all eligible 
Studies include the following: first author and year published, study location, study period, and sampling method, sample size, and laboratory testing method for HIV infection. Studies were categorized according to the geographical locations of Northern Africa and the type of population. Details of each study were entered into a database by one investigator with a $100 \%$ re-check. A quality assessment was carried out using a standard operating procedure [6].

Two trained epidemiologists (MA, MO) independently reviewed these publications and examined the sample size, sampling method, testing procedures, results, and interpretation of the data. Disagreements resolved by consensus or arbitration of a third author(AE). A quality score between 1 and 5 (the highest score was 5) was calculated for every paper on the basis of these criteria.

\section{Statistical and bio-data Analysis}

Statistical analysis was carried out by calculating confidence interval $(\mathrm{Cl})$, random-effects model, crude odds ratios $(\mathrm{OR})$, sensitivity analysis and cut-off $\mathrm{p}$-value $(p=0.1)$. Heterogeneity was tested by chi-square. The prevalence of HIV was calculated as an average of the pooled infection prevalence of each country weighted by the ratio of the country's population to the study's sample size in the survey data analysis. Risk of bias in reporting the prevalence and cumulative incidence was independently calculated by the authors. Publication bias was assessed by inspection of a funnel plot and Egger's test. Analyses of aggregated prevalence of each country were done with metan, command in which is an average of the individual study results weighted by the inverse of their variances using a fix/random model [19]. Geographic mapping was carried out using the national data in each country and localized clusters of spots reported as previously published[ 20,21].

\section{Results}

A total of 721 records were identified during the 10 years period (2008-2017), after elimination of duplicate, 646 studies were remained. When the titles and abstracts were screened a 598 irrelevant records were excluded and only 48 were assessed for eligibility of which 7 were excluded and only 41 were finally included in meta-analysis. Figure 1, illustrated the flow of the diagram for study selection. There was steady increase in the number of publications and HIV records in NA with slight increase in the last two years. The highest number of publication and HIV data notification was reported in Morocco, Egypt, Sudan and to less extent in Algeria , Tunisia and very low in Libya and Mauritania. The characteristic of included studies are presented in Table 1 . The forty-one studies were cross sectional and cohort in design and carried between 2008 and 2017.

The study quality assessment have shown that an overall, there were $n=7$, low quality where no full text available, $n=$ moderate quality and $n=$ high quality studies. However, after conducting analysis according to quality assessment, there were no significant difference between of high /medium quality studies and low or medium studies . 


\section{Temporal Trends of HIV/AIDS in North Africa}

During the study period (2008-2017), there was an increasing trend in the prevalence of HIV/AIDS within the Northern African region with great variation among the countries within the region Figure 2, shows the prevalence of HIV/AIDS in each North African country during the study period. In 2008, the highest prevalence was reported in Sudan (1.3\%) followed by Algeria(1.2\%) and Mauritania(1.3 \%)[22-24] . Although it was less than $1 \%$ in Tunisia ( $0.9 \%$ ), Morocco ( $0.3 \%$ ) Egypt ( $0.2 \%$ ) and Libya( $0.2 \%)$ [25-28]. In ten years period (2017), the overall prevalence was increased significantly $(P<0.001)$ to reach more than four times that of 2008. The highest prevalence was reported in Sudan (4.3\%), followed by Mauritania (2.3\%), Algeria (2.2 \%), Egypt (1.8\%),Morocco (1.6\%),Tunisia (1.2\%) and Libya (0.9\%). The overall prevalence of HIV among the North African countries varies greatly from one country to another and within the population of the same country in the studies analysed as illustrated in Forest plot-Figure 3. There was a clear relationship between the prevalence of HIV and attributable risk factors. General population and ordinary patients have low HIV prevalence comparable to other studied groups. For instances studies from blood donors, pregnant women carried in Egypt, Mauritania, Sudan, morocco, and those carried on General population in Libya, Tunisia and Algeria showed a low HIV prevalence which elevated on the risk groups within the same country. The overall odds ratio in the meta-analysis demonstrated a statistically significant variation among the population studied. The association appears a bit stronger in the studies related to high-risk groups. The test of heterogeneity showed a significant variation among the included studies indicating the nature and quality of these studies.

\section{Demographic features of HIV/AIDS in North Africa}

Figure 4 illustrated the gender and age specific distribution of HIV/AIDS among Northern African countries, Within the HIV/AIDS reported cases from 2008 till 2017, 76.9\% were male and $25.1 \%$ were female, with a male to female ratio of (M:F 3.1: 1). Although such prevalence among most of the North African countries, the number of the infected females was similar to male mainly in Morocco. The number of HIV/AIDS cases were predominantly reported among young individuals aged between 21 and 30 years old which reached $45 \%$ followed by meddle aged group (31- 40 years) at prevalence of 30 $\%$. A remarkable increase in the number of HIV/AIDS cases was reported among a younger patients aged less than 20 years particularly in Sudan, Algeria and Morocco. In addition the prevalence of HIV/AIDS infected cases of those aged above 40 years was steady among all countries at $20 \%$ a part from Libya which showed slight increase to reach $30 \%$. Few studies reported from Libya, Morocco and Sudan has reported on the education level and marital status of HIV/AIDS cases. Most of the infected cases were found predominantly among unmarried individual who were mainly, illiterate or with a low level of education[29-32].

\section{Prevalence HIV among risk population}

Figure 5 shows the prevalence of HIV/AIDS among high risk group populations within the Northern African countries. The highest prevalence was reported among PWID with an estimated median of $8 \%$ ranging from $3.80 \%, 95 \% \mathrm{Cl}(2.46-4.67 \%)$ to be $15.7 \%, 95 \% \mathrm{Cl}(9.46-18.67 \%)$. This is particularly high in 
Morocco Egypt, Sudan and Libya. HIV/AIDS among Sexual Promiscuity was also reported to be on an average of $2.8 \%(1.7-11.3 \%)$. It found to be $4.9 \%$ in Morocco, Algeria, Tunisia and Egypt and higher than $10.5 \%$ in Tunisia and Sudan [33-36]. Among the Prisoners, it was reported to be high in Libya, Sudan and Egypt although it was less than that in Mauritania, and Algeria. HIV was also reported to be high in Hospital care setting in Northern African countries ranging from 0.8 to $9.7 \%$.[37-41]. The highest was reported in Mauritania, Algeria, Egypt, followed by Sudan Tunis and Morocco and Libya.

\section{Distribution of HIV-1 subtypes}

Based on our data, genotype distribution of HIV in the seven Northern African countries is shown in Figure 6. Analysis of HIV-1 subtypes distribution in is very poor particularly in Algeria, Mauritania, where only one study was reported for each of them[42,43]. The Tunisian sequences belongs to , Six HIV-1 subtypes (B, A1, G, D, C, and F2), five circulating recombinant forms (CRF02_AG, CRF25_cpx, CRF43_02G, CRF06_cpx and CRF19_cpx) and 11 unique recombinant forms were identified. Subtype B (46.4\%) and CRF02_AG (39.4\%) were the predominant genetic forms[44]. A genetic analysis of HIV-1 strains in Libya demonstrated low subtype heterogeneity with the evolution of subtype $B$ which composed of $74 \%$ followed by , CRF_20 AG(18\%) , as well as HIV-1 subtype A(8\%)[RR]. In Sudan it was found that $50 \%$ were subtype $D$ and $30 \%$ were subtype $C$. Subtype $A$, subtype $B$, and three unique recombinants were also found, some partially unclassifiable[45-47]. While in Morocco, subtype $B$ is the predominant one $(76.7 \%)$, followed by a high diversity of non-B subtypes, especially CRF02_AG recombinant (15\%), and to less extent Subtype $A(1.0 \%)$ and $F$ strains $(0.5 \%)$. Egypt; The commonly isolated strains form Egypt was Subtype B composed of 95\% followed CRF01_AE ( $1 \% 0$ and A (1\%). In Algeria , we observed high HIV-1 diversity with a predominance of the B subtype followed by CRF02_AG and CRF06_cpx.5,6. Studies have indicated that, the diversity was maintained, but CRF06_cpx became widely predominant. The Phylogenetic analysis of different strains in Mauritania revealed CRF02_AG ( $64.6 \%$ ) was the predominant stain followed by B variants with the predominance of $10 \%$.

\section{Geospatial distribution of HIV/AIDS in North Africa}

HIV/AIDS infections spread gradually from the capital coastal cities to the other regions of Northern Africa countries. Figure 7, display the spatial distribution of HIV-seropositive individuals living in North African between 2008 and 2017[48-51]. There is a clear change in the regional patterns of HIV with a significant spatial heterogeneity within each country. The substantial variability ranged from a low of 0.01 percent to $5 \%$ with no clear regional patterning of the space-time interaction.

A higher level was reported in Sudan, Morocco and Algeria and to less extent Mauritania and Tunis. Although the patterning persists in Libya and Egypt. In Sudan, the HIV patterns reached its highest in Southern regions, It is estimated that HIV prevalence in the 10 states that now make up South Sudan was 3.0\%, ranging from zero in Northern Bahr el Ghazal to $7.2 \%$ in Western Equatoria State(WES). 
Followed by Kassala State- Eastern Sudan, (0.2-3\%), Khartoum (0 to 5.7\%.), Gadarif State (0.1-0.4\%), Kosti (0.1-0.7\%).

In Morocco the highest was reported in Agadir Souss-Massa-Drâa,-SOUTH , Fes, Rabat in the central region followed by Nador and Tanger, in north and Marrakech in the south west.

In Egypt the prevalence was high in East Cairo Sector followed by Alexandria and South Sinai. Though in Libya was high both in Eastern and western coasts followed by Central south of Sebha area. In Tunisia the prevalence was the highest in the capital, Bizerte and Hammamet, followed by other coastal cities of Sousse and Sfax , though its less in meddle and the southern regions of the country. In Algeria, Northeastern Algeria reported the highest HIV prevalence particularly in the neighboring area of Tunis. Followed by Oran and Sidi Bel Abbes. Such prevalence was less in the central and southern regions of Algeria. In Mauritania, HIV prevalence reached its highest (1-2\%)in Nouakchott area followed by the central region though no data available on most of Eastern regions and Western Sahara.

The North African countries has experienced high-risk clustering areas of HIV/AIDS cases during the 10 year study period. Figure 8 shows the Distribution of HIV spatial clustering in the region; Areas in dark red indicate statistically significant hotspots of higher than expected rates. The results of spatio-temporal cluster analysis suggested a special characteristic in temporal and spatial distribution for HIV/AIDS incidents. A total of ELEVEN statistically significant high-risk areas, at different periods were reported in several regions and provinces of the seven counties.

In Morocco has experienced two clusters, the highest spatio-temporal cluster area was located in Agadir Souss-Massa-Drâa,-at the south in 2011 and Fes, Rabat in the central region followed by Nador and Tanger, . The second one, in the north at 2012 and Marrakech in the south west at 2014. The main clusters were reported among PWID followed by MSM and FSWs. For PWID networks contributed to (6\%; $95 \% \mathrm{Cl} 3-10 \%)$, most transmission appears to be in the north of Morocco. The epidemic in commercial heterosexual sex networks and MSM appears to be most intense in the south of Morocco, and especially in Souss-Massa-Drâa. The largest contribution to HIV incidence was among clients of FSWs (25\%; $95 \%$ confidence interval ( $\mathrm{Cl}) 14-37 \%)$, followed by MSM (22\%; $95 \% \mathrm{Cl} 12-35 \%)$, stable heterosexual couples (corresponding to HIV serodiscordant couples; $22 \%$; $95 \% \mathrm{Cl} 12-34 \%$ ), and FSWs (11\%; $95 \% \mathrm{Cl} 6-18 \%$ ).

In Sudan, The biggest cluster was reported in Southern Sudan at Western Equatoria State(WES)-2012. Among 420 antenatal clinic attendees, HIV seropositivity was $10.7 \%(95 \%, \mathrm{Cl}=8.0 \%-14.2 \%)$, and among 388 voluntary counseling and testing attendees, HIV sero-positivity was $13.1 \%(\mathrm{Cl}=10.0 \%-$ 17.0\%), indicating high HIV prevalence in WES.

In Libya three clusters were reported between 2008-2017, the first cluster occurred during 2008-2012, consisted of 203 cases and It was located in Tripoli in the western region. The second one was reported in Musrata (largest in the central region) and consisted of 406 HIV cases detected between 2013 and 2017. While the third cluster was detected in Sebha( the largest city in the South) between 2013 and 2017 and consisted of 317 HIV cases. 
In 2011, Egypt has experienced a concentrated epidemic among MSM and IVDUs in East Cairo Sector, Alexandria and South Sinai. The HIV prevalence ranged from (5.4\% to 6.9\% and 6.9\% among MSM though it was (6.7-7.7\%) in IVDUs.

Minor clusters were reported in Algeria, Tunisia and Mauritania A study (2013) carried in two hospitals in Northeastern Algeria reported a high clustering of HIV among pregnant women with a prevalence rate reached up to prevalence of 5.3/1000. In Tunisia however, a small cluster was reported among at the North of the country particularly within in the capital Tunis which was mainly associated with FMSW and MSM in 2 011. As well as In Mauritania a minor cluster was reported among blood donors in December 2015 at Hodh El Gharbi region which is located $800 \mathrm{~km}$ from Nouakchott (capital) South-East of the country.

\section{Discussion}

The actual status of HIV infection patterns in Northern Africa countries have been subjected to debate and perturbation. There is paucity of data regarding the HIV prevalence in the region and no formal a national population based surveillance studies were done a part from those carried in Libya and Morocco $[20,26]$. Worryingly, health planners and strategists in this region are still less judgmental with the ongoing HIV epidemic situation. Even, the cultural understanding and social perception still not waken up toward the serious consequences of the epidemic. Infected individuals particularly women, often facing denial of care, stigmatizing attitudes, discrimination, and breaches of confidentiality [52].

In this review, we comprehensively analyzed the actual situation of HIV prevalence in Northern African countries, HIV incidence has increased significantly in the region over the last ten years. The overall prevalence ranged from $0.2 \%$ to $1.4 \%$ in 2008 to reach up to $4.4 \%$ in 2017 . The highest prevalence was reported in Sudan, Algeria, Mauritania and Egypt followed by Morocco, Tunisia and Libya. However, Figures in certain countries raise concern about their reliability. For instance, the prevalence in Egypt, the largest populated country in the region ( over 100 millions), Algeria ( 45 millions) and Tunisia ( 15 millions ) are much lower than that of Sudan ( 38 millions) or Morocco (36 millions) and even in Mauritania (Four Millions). Despite all that, the HIV epidemic seems to be alarming particularly in Algeria, Sudan, Mauritania and Morocco.

In the region, there is a paucity of research in marginalized groups such as men who have sex with men and sex workers particularly in Algeria, Egypt and Mauritania. The data on people who inject drugs are even sparser particularly in Libya, Mauritania and Algeria. However, emerging data from Morocco and Sudan suggests that HIV prevalence is significantly higher in these groups than in the general population. Hence then further studies at a national and regional levels are needed [53].

Different demographic factors were reported to influence the prevalence of HIV among Northern African populations. The highest prevalence was reported among the younger individuals. Over $45 \%$ of HIV cases was reported with those aged (21-30 years ), followed by meddle aged group (31- 40 years) at prevalence of $30 \%$. Most of the infected cases were found predominantly among unmarried individuals 
who were mainly, illiterate or with a low level of education. However, no country a part form Sudan reported HIV infection among children younger than 5 years despite that mother-to-child transmission is evident. Furthermore, steady increase within older age was reported particularly in Libya. it is clearly obvious that the epidemic is not any more confined to males in the region. A considerable number of females are also affected. In Morocco, Sudan, and Tunisia the prevalence of HIV among women seems to be exceeding that of men. Studies in sub-Saharan Africa have shown that Adolescent girls and young women have up to eight fold higher rates of HIV infection compared to their male peers [54-56]. However, there remains a gap in women initiated HIV prevention technologies for young women in Northern African countries

The patterns of HIV transmission have evolved over time and the epidemic concentration varied from one country to another in the Northern African region. Cases among blood donors have been eliminated in Morocco, Tunisia and Libya, less reported in Egypt. Though, they are still reported in Mauritania, Sudan and Algeria. Although the prevalence was higher among health care settings in Most of the countries. However, the HIV epidemic is currently concentrated in injection drug users and female sex workers particularly in Morocco, Egypt, Tunisia and Algeria .Although it was less in in Libya "Mauritania and Sudan where Prisoners is the main factor. This demographic variability is similar to other nations such as Sub-Saharan Countries [57,58]. These findings indicated that injection drug use might be the major risk factor for HIV transmission in the region. This is probably due to shared drug paraphernalia [ 59]. Hence then, understanding the HIV dynamics within Northern African is an important step towards facing the consequence challenges of this epidemic.

HIV sequences from cases identified in the NA countries have been sporadically published, providing a mosaic overview of the molecular epidemiology of HIV in the region. The epidemic in Algeria, Morocco, Mauritania and Tunisia was dominated by subtype B and CRF02_AG,in addition toCRF06_cpx in Algeria. In Libya $75 \%$ of reported cases were Subtype B and (18\%) CRF_20 AG. Though in Sudan it was found that $50 \%$ were subtype D and $30 \%$ were subtype C, while in Egypt Subtype B composed of $95 \%$. Given the wide distribution of subtypes in the region suggests that HIV-1 has been introduced multiple times in these countries. The broad array of subtypes/CRFs indicates that the epidemic is more complicated than in many other regions of the world, where one subtype usually predominates. Studies in North America and southern Africa, have shown that the main circulating subtypes represent more than $95 \%$ of all HIV-1 infections in these region[60,61] This however, could be reflected on the prevention strategies in the region. Furthermore, there is a lack of studying phylodynamics in tracing the origins and transmission routes of HIV infection in the region. This is a particularly important in arguable aspects as the HIV outbreak among Libyan children associated with Bulgarian Nurses saga [62 ]

Our study indicated clearly that spread of HIV varies greatly within Northern African countries showing stark geographical variations in the prevalence of HIV infection. However, there seems to be considerable inter- and intra-country variability, ranging from $0 \%$ in some parts of Libya and Tunisia to over $3 \%$ in the coastal area of Morocco Algeria and Southern Sudan. These observed spatial variations highlighted the clustering of HIV across the North African countries indicating that generalized epidemic may be evident 
in this region[63]. Certain pockets within the region harbor the threat of a generalized epidemic, as the virus spreads from the most-at-risk to the general population. However, Over elven clusters were reported. The driving dynamic factor of these clusters were mainly FSW and IVDUS particularly in Morocco, Tunisia and Egypt though IVDUS in Libya. While the incidences reported in Algeria, Mauritania and Sudan were associated with pregnant women, blood donation antenatal clinic. These findings should be considered for future research and clinical practice[64]. Public health policy makers should give careful consideration to the substantial variation shown by the spread of HIV through populations and communities within each country when formulating HIV control measures. This is especially important if one considers that there is no single global HIV epidemic. The Joint United Nations Program on HIV/ AIDS has adopted the mantra "Know your epidemic; know your response'[65].

The findings of this review shed light on key features of the epidemic in Northern African country, but several gaps remain unresolved. There is a gap of research related to mortality due HIV in the region particularly among HIV-infected children and no studies were carried on mother to-child transmission . Hence then emphasis needs to be placed on diagnosing and treating HIV infection in pregnant women to prevent perinatal transmission, screening early for HIV infection in infants born to HIV-infected mothers, and treating those who are infected before they develop more advanced disease as the world moves toward the goal of eliminating mother to-child transmission of HIV[66]. Furthermore, most of these countries are plugged by internal conflicts and have persistent difficulty in addressing healthcare needs. Thus, immigrants refugees, Internally Displaced Persons and Insurgent Groups may have a role in the spread of HIV in region. However, further studies are needed as data from sub Saharan African countries suggest that reconstruction periods after conflict might be a more vulnerable time for HIV transmission than during conflict [67-69].

The Limitations of meta-analysis is generally applicable here. One of the challenges encountered in this review was the fact that the studies adopted different methods, duration and populations categories. The quality assessment of the studies that composed this review show that most studies obtained a medium-quality rating and few of them obtained a high score, which indicates more rigorous research studies are needed Different contribution factors, which we did not analyze in most of the countries are level of education and personnel income of the HIV infected individuals. Female sex workers and Man having sex with men (MSM) cannot even easily followed or even mentioned particularly in Libya and Mauritania as these acts are prohibited and considered to be crime may lead to death penalty[$[70,71]$.

In conclusion, HIV is in an alarming status in the Northern African countries and they are facing serious epidemics. Sudan, Egypt, Morocco, and Algeria having concentrated epidemics which is comparably low in Mauritania, Libya and Tunisia.. Furthermore they are stepping toward a concentrated clusters that has been challenged and hampered by massive population displacement associated with the chaotic economic and socio-political situations The endemicity of HIV in these countries is complicated by lack of registry data and follow up programs particularly in the Sahara and countryside areas. Abetted by the UNAIDS definition of generalized epidemics having HIV prevalence of more than $1 \%$ in the adult general population (aged 15-59) and more than 5\% in adult vulnerable groups [72]. Hence a generalized 
epidemic persists in Sudan in particular and even Algeria, Morocco and Egypt. There is an urgent need to establish standardized epidemiological platform both at the national and regional levels that can reliably quantify individual differences in risk, understand the chain of HIV transmission and geographic clusters of HIV. Few studies have examined how geographic disparities may impact trends in HIV-seropositive cases in Northern African countries. Identifying such social and geographic factors are important for better screening , treatment and thus reducing the burden of high- risk population[20,73,74].

\section{Abbreviations}

AIDS: acquired immune deficiency syndrome; ART: antiretroviral therapy; HIV: human immunodeficiency virus; PRISMA: preferred reporting items for systematic reviews and meta-analyses; NA: North Africa; WHO: World Health Organization.

\section{Declarations}

\section{Ethical approval and consent to participate}

An ethical approval was not required for this study as it was based on data/information retrieved from published studies already available in the public domain.

\section{Author contributions}

Conceived and designed the experiments: MD. Analyzed the data: MD NS \& AE. Contributed materials/analysis tools: MD, MO, and AE. Wrote the paper: MD. Designed the analysis: MD . Performed cartography: MD and AE. Provided advice and critically reviewed the manuscript: MD, MO \& NS.

\section{Competing interests}

The authors declare that they have no competing interests.

\section{Acknowledgements}

We are deeply grateful to the Libyan Study Group of Hepatitis\& HIV and the Department of Medical Microbiology \& Immunology, Faculty of Medicine, University of Tripoli.

\section{Consent for publication}

Not applicable.

\section{Availability of data and material}

The data presented in this paper are freely available upon request. 


\section{Funding}

No funding was received for this study.

\section{References}

1. Piot P, Quinn TC. Response to the AIDS pandemic-a global health model. New England Journal of Medicine. 2013 Jun 6;368(23):2210-8.

2. Blood GA. Human immunodeficiency virus (HIV). Transfusion Medicine and Hemotherapy. 2016 May;43(3):203.

3. Gökengin D, Doroudi F, Tohme J, Collins B, Madani N. HIV/AIDS: trends in the Middle East and North Africa region. International Journal of Infectious Diseases. 2016 Mar 1;44:66-73.

4. Fortson JG. Mortality risk and human capital investment: The Impact of HIV/AIDS in Sub-Saharan Africa. The Review of Economics and Statistics. 2011 Feb 1;93(1):1-5.

5. Kharsany $A B$, Karim QA. HIV infection and AIDS in sub-Saharan Africa: current status, challenges and opportunities. The open AIDS journal. 2016;10:34.

6. Poteat T, Ackerman B, Diouf D, Ceesay N, Mothopeng T, Odette KZ, Kouanda S, Ouedraogo HG, Simplice A, Kouame A, Mnisi Z. HIV prevalence and behavioral and psychosocial factors among transgender women and cisgender men who have sex with men in 8 African countries: A crosssectional analysis. PLoS medicine. 2017 Nov 7;14(11):e1002422.

7. Tengan FM, Abdala E, Nascimento M, Bernardo WM, Barone AA. Prevalence of hepatitis B in people living with HIV/AIDS in Latin America and the Caribbean: a systematic review and meta-analysis. BMC infectious diseases. 2017 Dec 1;17(1):587. 
8. Esterhuysen P, editor. Africa a to z: Continental and country profiles. Africa Institute of South Africa; 2013 Dec 7.

9. Daw MA, El-Bouzedi A, Dau AA. Libyan armed conflict 2011: mortality, injury and population displacement. African Journal of Emergency Medicine. 2015 Sep 1;5(3):101-7.

10. Daw MA, El-Bouzedi A, Dau AA. The assessment of efficiency and coordination within the Libyan health care system during the armed conflict-2011. Clinical Epidemiology and Global Health. 2016 Sep 1;4(3):120-7.

11. Daw MA, El-Bouzedi A, Ahmed MO, Dau AA, Agnan MM, Drah AM, Deake AO. Prevalence of human immune deficiency virus in immigrants crossing to Europe from North and Sub-Saharan Africa. Travel Med Infect Dis. 2016 Nov 1;14(6):637-8.

12. Gökengin D, Doroudi F, Tohme J, Collins B, Madani N. HIV/AIDS: trends in the Middle East and North Africa region. International Journal of Infectious Diseases. 2016 Mar 1;44:66-73.

13. Granich R, Gupta S, Hersh B, Williams B, Montaner J, Young B, Zuniga JM. Trends in AIDS deaths, new infections and ART coverage in the top 30 countries with the highest AIDS mortality burden; 1990-2013. PloS one. 2015 Jul 6;10(7):e0131353.

14. Rutledge SE, Whyte J, Abell N, Brown KM, Cesnales NI. Measuring stigma among health care and social service providers: The HIV/AIDS provider stigma inventory. AIDS patient care and STDs. 2011 Nov 1;25(11):673-82.

15. Karamouzian M, Madani N, Doroudi F, Haghdoost AA. Improving the quality and quantity of HIV data in the Middle East and North Africa: key challenges and ways forward. International Journal of Health Policy and Management. 2017 Feb;6(2):65. 
16. Setayesh H, Roudi-Fahimi F, El Feki S, Ashford LS. HIV and AIDS in the Middle East and North Africa. Washington, DC: Population Reference Bureau. 2014 Jun.

17. Panic N, Leoncini E, De Belvis G, Ricciardi W, Boccia S. Evaluation of the endorsement of the preferred reporting items for systematic reviews and meta-analysis (PRISMA) statement on the quality of published systematic review and meta-analyses. PloS one. 2013 Dec 26;8(12):e83138.

18. Shamseer L, Moher D, Clarke M, Ghersi D, Liberati A, Petticrew M, Shekelle P, Stewart LA. Preferred reporting items for systematic review and meta-analysis protocols (PRISMA-P) 2015: elaboration and explanation. Bmj. 2015 Jan 2;349.

19. Daw MA, Daw AM, Sifennasr NE, Draha AM, Daw AM, Daw AM, Ahmed MO, Mokhtar ES, El-Bouzedi A, Daw IM. The epidemiology of hepatitis D virus in North Africa: a systematic review and metaanalysis. The Scientific World Journal. 2018 Jan 1;2018.

20. Daw MA, Daw AM, Sifennasr NE, Draha AM, Daw AA, Daw AA, Ahmed MO, Mokhtar ES, El-Bouzedi AH, Daw IM, Adam SI. Spatiotemporal analysis and epidemiological characterization of the human immunodeficiency virus (HIV) in Libya within a twenty five year period: 1993-2017. AIDS research and therapy. 2019 Dec;16(1):1-9

21. Kouyoumjian SP, El Rhilani H, Latifi A, El Kettani A, Chemaitelly H, Alami K, Bennani A, Abu-Raddad LJ. Mapping of new HIV infections in Morocco and impact of select interventions. International Journal of Infectious Diseases. 2018 Mar 1;68:4-12.

22. Badawi MM, Atif MS, Mustafa YY. Systematic review and meta-analysis of HIV, HBV and HCV infection prevalence in Sudan. Virology journal. 2018 Dec;15(1):1-6. 
23. Ouyahia A, Rais M, Gasmi A, Guenifi W, Mechakra S, Lacheheb A. HIV/AIDS epidemic features and trends in setif city (Algeria) from 1986 to 2009. Retrovirology. 2010 May;7(1):1-.

24. Boushab BM, Limame OC, Zahra FM, Mamoudou S, Darnycka BM, Saliou SM. Estimation of seroprevalence of HIV, hepatitis B and C virus and syphilis among blood donors in the hospital of Aïoun, Mauritania. Pan African Medical Journal. 2017;28(1):145.

25. Kilani B, Ammari L, Marrakchi C, Letaief A, Chakroun M, Jemaa B, HT BA, Kanoun F, Chaabène B. Seroepidemiology of HCV-HIV coinfection in Tunisia. La Tunisie medicale. 2007 Feb 1;85(2):121-3.

26. Kouyoumjian, S.P., Mumtaz, G.R., Hilmi, N., Zidouh, A., El Rhilani, H., Alami, K., Bennani, A., Gouws, E., Ghys, P.D. and Abu-Raddad, L.J., 2013. The epidemiology of HIV infection in Morocco: systematic review and data synthesis. International journal of STD \& AIDS, 24(7), pp.507-516

27. Soliman HH, Almotgly MM. Psychosocial profile of people with AIDS and their caregivers in Egypt. Psychological reports. 2011 Jun;108(3):883-92.

28. Daw MA, El-Bouzedi A, Ahmed MO, Dau AA. Molecular and epidemiological characterization of HIV-1 subtypes among Libyan patients. BMC Research Notes. 2017 Dec;10(1):1-9

29. Mohamed BA, Mahfouz MS. Factors associated with HIV/AIDS in Sudan. BioMed research international. 2013 Jan 1;2013.

30. Fall-Malick FZ, Bara AO, Lam M, Beibacar MM, Ba K, Ba H, Ghady IO, Horma AO, Toure-Kane NC, Mboup S, Lo B. HIV sentinel surveillance of pregnant women in Mauritania from 2001 to 2007. Bulletin de la Société de Pathologie Exotique. 2010;103(4):243-5 
31. Aidaoui M, Bouzbid S, Laouar M. Seroprevalence of HIV infection in pregnant women in the Annaba region (Algeria). Revue d'epidemiologie et de sante publique. 2008 Aug;56(4):261.

32. Daw MA, Shabash A, El-Bouzedi A, Dau AA. Seroprevalence of HBV, HCV \& HIV co-infection and risk factors analysis in Tripoli-Libya. PloS one. 2014 Jun 17;9(6):e98793.

33. Henry E, Bernier A, Lazar F, Matamba G, Loukid M, Bonifaz C, Diop S, Otis J, Préau M, Partages Study Group. "Was it a mistake to tell others that you are infected with HIV?": Factors associated with regret following HIV disclosure among people living with HIV in five countries (Mali, Morocco, Democratic Republic of the Congo, Ecuador and Romania). Results from a community-based research. AIDS and Behavior. 2015 Feb 1;19(2):311-21.

34. Tebourski F, Alaya DB. Knowledge and attitudes of high school students regarding HIV/AIDS in Tunisia: does more knowledge lead to more positive attitudes?. Journal of adolescent health. 2004 Mar1;34(3):161-2.

35. Kabbash IA, Abdul-Rahman I, Shehata YA, Omar AR. HIV infection and related risk behaviours among female sex workers in greater Cairo, Egypt. Eastern Mediterranean health journal. 2012 Sep 1;18(9).

36. Dean JA. Sexual health knowledge, attitudes, and beliefs of Queensland Sudanese communities(Doctoral dissertation, PhD thesis, School of Nursing and Midwifery, Griffith University).

37. Bozicevic I, Guezzar F, Stulhofer A, Bennani A, Handanagic S, Barbaric J, El Rhilani H, Alami K, Khattabi $\mathrm{H}$, Riedner $\mathrm{G}$, Maaroufi A. HIV prevalence and related risk behaviours in female seasonal farm workers in Souss Massa Draa, Morocco: results from a cross-sectional survey using clusterbased sampling. Sexually transmitted infections. 2018 Nov 1;94(7):515-7. 
38. Mohamed HI, Saad ZM, Abd-Elreheem EM, Abd-ElGhany WM, Mohamed MS, Abd Elnaeem EA, Seedhom AE. Hepatitis C, hepatitis B and HIV infection among Egyptian prisoners: seroprevalence, risk factors and related chronic liver diseases. Journal of infection and public health. 2013 Jun 1;6(3):186-95.

39. Kabbash IA, Ali EA, Elgendy MM, Abdrabo MM, Salem HM, Gouda MR, Elbasiony YS, Elboshy N, Hamed M. HIV/AIDS-related stigma and discrimination among health care workers at Tanta University Hospitals, Egypt. Environmental Science and Pollution Research. 2018 Nov 1;25(31):30755-62.

40. Ba K, Keita M, Fall-Malick FZ, Beibakar MM, Diallo M, Lo BB. Serological and behavioral survey on HIV/AIDS among prisoners in Nouakchott (Mauritania). Bulletin de la Societe de pathologie exotique (1990). 2015 Aug;108(3):208-12.

41. Courtney LP, Goco N, Woja J, Farris T, Cummiskey C, Smith E, Makuach L, Chun HM. HIV prevalence and behavioral risk factors in the Sudan People's Liberation Army: Data from South Sudan. PloS one. 2017 Nov 21;12(11):e0187689.

42. Abdellaziz A, Papuchon J, Khaled S, Ouerdane D, Fleury H, Recordon-Pinson P. Predominance of CRF06_cpx and transmitted HIV resistance in Algeria: Update 2013-2014. AIDS Research and Human Retroviruses. 2016 Apr 1;32(4):370-2.

43. Fall-Malick FZ, Tchiakpé E, Ould Soufiane SA, Diop-Ndiaye H, Mouhamedoune Baye A, Ould Horma Babana A, Kane CT, Lo B, Mboup S. Drug resistance mutations and genetic diversity in adults treated for HIV type 1 infection in Mauritania. Journal of medical virology. 2014 Mar;86(3):404-10. 
44. El Moussi A, Thomson MM, Delgado E, Cuevas MT, Nasr M, Abid S, Ben Hadj Kacem MA, Benaissa Tiouiri H, Letaief A, Chakroun M, Ben Jemaa M. Genetic diversity of HIV-1 in Tunisia. AIDS Research and Human Retroviruses. 2017 Jan 1;33(1):77-81.

45. Lo Presti A, Farcomeni S, Fontanelli Sulekova L, Grieco S, Sernicola L, Baesso M, Maggiorella MT, Angeletti S, Foley B, Ciccozzi M, Taliani G. Characterization of HIV-1 Subtypes Among South Sudanese Patients. AIDS research and human retroviruses. 2019 Oct 1;35(10):968-71.

46. Boutros S, Skordis J. HIV/AIDS surveillance in Egypt: current status and future challenges. EMHJEastern Mediterranean Health Journal, 16 (3), 251-258, 2010. 2010.

47. Bouzeghoub S, Jauvin V, Recordon-Pinson P, Garrigue I, Amrane A, Belabbes EH, Fleury HJ. High diversity of HIV type 1 in Algeria. AIDS Research \& Human Retroviruses. 2006 Apr 1;22(4):367-72.

48. Baba SP, Ayat Jervase MS, Dokubo EK, Clarke K. Investigation of High HIV Prevalence in Western Equatoria State-South Sudan, 2012. MMWR. Morbidity and Mortality Weekly Report. 2013 Jun 7;62(22):453.

49. Kebe M, Fall-Malick FZ, Elghady OI, Ebnou OH, Bara OA, Lam M, Beibacar MO, Diallo MY, Keita M, Sy I, Bellaty AJ. HIV seroprevalence among STD patients in Nouakchott and Nouadhibou (Mauritania). Bulletin de la Societe de pathologie exotique (1990). 2011 Dec;104(5):374.

50. Himmich H, Ouarsas L, Hajouji FZ, Lions C, Roux P, Carrieri P. Scaling up combined community-based HIV prevention interventions targeting truck drivers in Morocco: effectiveness on HIV testing and counseling. BMC infectious diseases. 2015 Dec 1;15(1):208.

51. Soliman C, Rahman IA, Shawky S, Bahaa T, Elkamhawi S, Abd El Sattar A, Oraby D, Khaled D, Feyisetan B, Salah E, El Taher Z. HIV prevalence and risk behaviors of male injection drug users in Cairo, Aids. 2010 Jul 1;24:S33-8. 
52. Abdool Karim SS. Stigma impedes AIDS prevention. Nature 2011; 474(7349): 29-31. [http://dx.doi.org/10.1038/474029a] [PMID: 21637237]

53. Baral S, Beyrer C, Muessig K, et al. Burden of HIV among female sex workers in low-income and middle income countries: a systematic review and meta analysis. Lancet Infect Dis 2012; 12(7): 53849. [http://dx.doi.org/10.1016/S1473-3099(12)70066-X] [PMID: 22424777]

54. Leclerc PM, Garenne M. Commercial sex and HIV transmission in mature epidemics: a study of five African countries. Int J STD AIDS 2008; 19(10): 660-4.

55. Peltzer K. Early sexual debut and associated factors among in school adolescents in eight African countries. Acta Paediatr 2010; 99(8): 1242-7. [http://dx.doi.org/10.1111/j.1651-2227.2010.01874.x] [PMID: 20491706]

56. Chen L, Jha P, Stirling B, et al. Sexual risk factors for HIV infection in early and advanced HIV epidemics in sub-Saharan Africa: systematic overview of 68 epidemiological studies. PLoS One 2007; 2(10): e1001. [http://dx.doi.org/10.1371/journal.pone.0001001] [PMID: 17912340]

57. Nnko S, Kuringe E, Nyato D, Drake M, Casalini C, Shao A, Komba A, Baral S, Wambura M, Changalucha J. Determinants of access to HIV testing and counselling services among female sex workers in sub-Saharan Africa: a systematic review. BMC public health. 2019 Dec 1;19(1):15.

58. Seidu AA, Oduro JK, Ahinkorah BO, Budu E, Appiah F, Baatiema L, Ameyaw EK, Sambah F. Women's decision-making capacity and HIV testing in sub-Saharan Africa: A multi-country analysis of Demographic and Health Surveys.

59. Clatts MC, Heimer R, Abdala N, Goldsamt LA, Sotheran JL, Anderson KT, Gallo TM, Hoffer LD, Luciano PA, Kyriakides T. HIV-1 transmission in injection paraphernalia: heating drug solutions may inactivate HIV-1. Journal of Acquired Immune Deficiency Syndromes (1999). 1999 Oct 1;22(2):194-9. 
60. Tengan FM, Abdala E, Nascimento M, Bernardo WM, Barone AA. Prevalence of hepatitis B in people living with HIV/AIDS in Latin America and the Caribbean: a systematic review and meta-analysis. BMC infectious diseases. 2017 Dec 1;17(1):587.

61. Rolland M, Modjarrad K. Multiple co-circulating HIV-1 subtypes in the Middle East and North Africa. AIDS (London, England). 2015 Jul 17;29(11):1417.

62. Hemelaar J, Gouws E, Ghys PD, Osmanov S, Isolation Nf. Characterisation. Global trends in molecular epidemiology of HIV-1 during 2000-2007. AIDS 2011; 25:679-689.

63. Boyda DC, Holzman SB, Berman A, Grabowski MK, Chang LW. Geographic Information Systems, spatial analysis, and HIV in Africa: A scoping review. PloS one. 2019 May 3;14(5):e0216388.

64. Manda S, Haushona N, Bergquist R. A Scoping Review of Spatial Analysis Approaches Using Health Survey Data in Sub-Saharan Africa. International journal of environmental research and public health. 2020 Jan;17(9):3070.

65. Wilson D, Halperin DT. "Know your epidemic, know your response": a useful approach, if we get it right. The Lancet. 2008 Aug 9;372(9637):423-6.

66. Adetokunboh 00, Oluwasanu M. Eliminating mother-to-child transmission of the human immunodeficiency virus in sub-Saharan Africa: The journey so far and what remains to be done. Journal of infection and public health. 2016 Jul 1;9(4):396-407. 
67. Spiegel PB, Bennedsen AR, Claass J, Bruns L, Patterson N, Yiweza D, Schilperoord M. Prevalence of HIV infection in conflict-affected and displaced people in seven sub-Saharan African countries: a systematic review. The Lancet. 2007 Jun 30;369(9580):2187-95.

68. Spiegel PB. HIV/AIDS among conflict-affected and displaced populations: dispelling myths and taking action. Disasters 2004; 28: 322-39.

69. Spiegel PB, Checchi F, Colombo S, Paik E. Health-care needs of people affected by conflict: future trends and changing frameworks. The Lancet. 2010 Jan 23;375(9711):341-5.

70. Siegfried N, Clarke M, Volmink J (2005) Randomised controlled trials in Africa of HIV and AIDS: descriptive study and spatial distribution. BMJ 331: 742.

71. Egger M, Davey-Smith G (1998) Meta-analysis: Bias in location and selection of studies. BMJ 316 : 61-6.

72. UNAIDS (2006) AIDS Epidemic Update. Geneva: WHO/UNAIDS.

73. Cuadros DF, Li J, Mukandavire Z, Musuka GN, Branscum AJ, Sartorius B, Mugurungi O, Tanser F. Towards UNAIDS Fast-Track goals: targeting priority geographic areas for HIV prevention and care in Zimbabwe. Aids. 2019 Feb 1;33(2):305-14.

74. Nunn A, Yolken A, Cutler B, Trooskin S, Wilson P, Little S, Mayer K. Geography should not be destiny: focusing HIV/AIDS implementation research and programs on microepidemics in US neighborhoods. American Journal of Public Health. 2014 May;104(5):775-80.

\section{Table}

Table 1: Characteristics of HIV-studies included in meta-analysis 


\section{Country}

-Algeria

-Egypt

-Libya

-Mauritania

-Morocco

-Sudan

-Tunisia

Study design

-Cross section

- Cohort study

\section{Data collection}

- Prospective

- Retrospective

Study area(site)

-Hospital oriented

- Population oriented

Sampling method

-Random

-Consecutive

- Not reported
30

19

\section{Number of the studies}

4

7

6

2

11

7

4

11

32

9

22

21

14

6

\section{Figures}



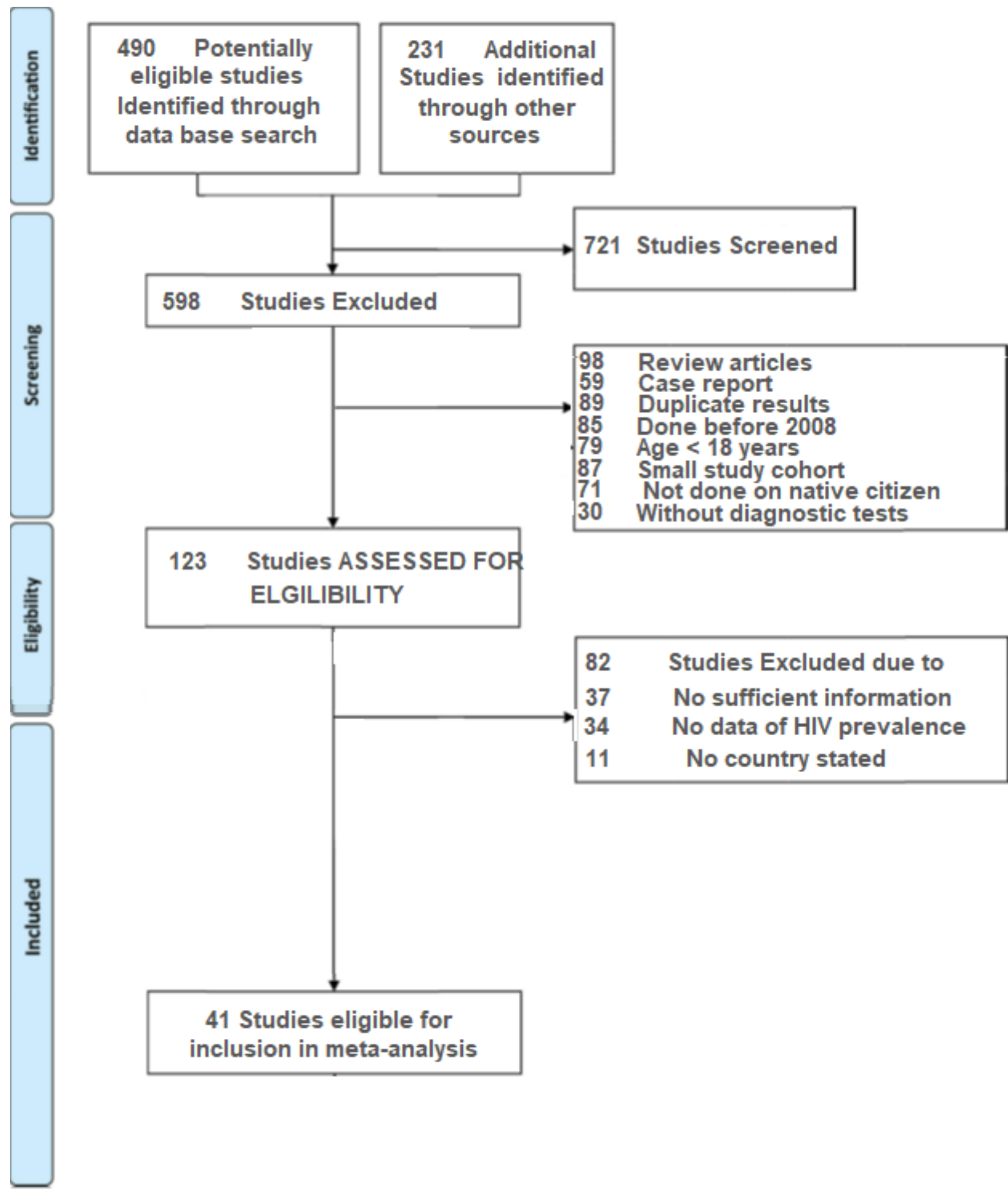

\section{Studies ASSESSED FOR ELGILIBILITY}

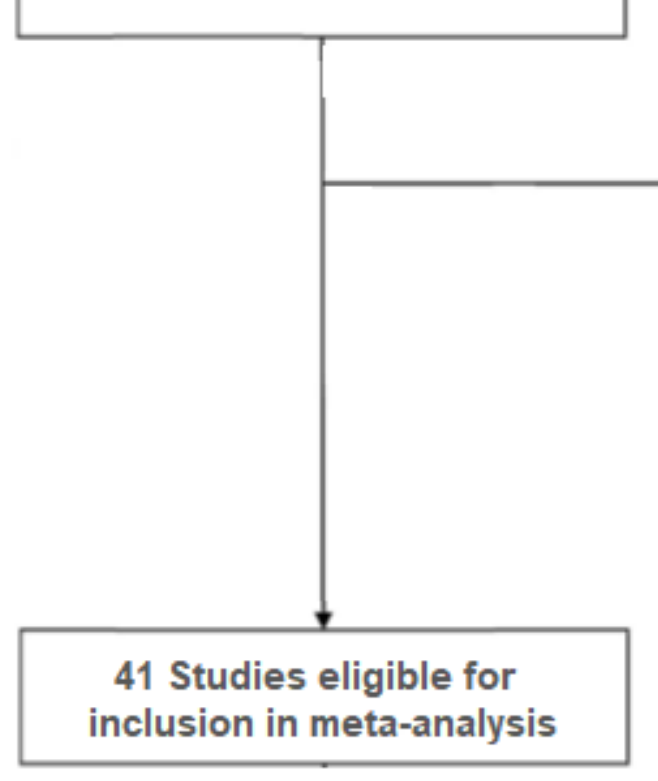

Figure 1

Selection of studies of HIV/AIDS epidemiology in North Africa, 2008-2017, for inclusion in metaanalysis. 


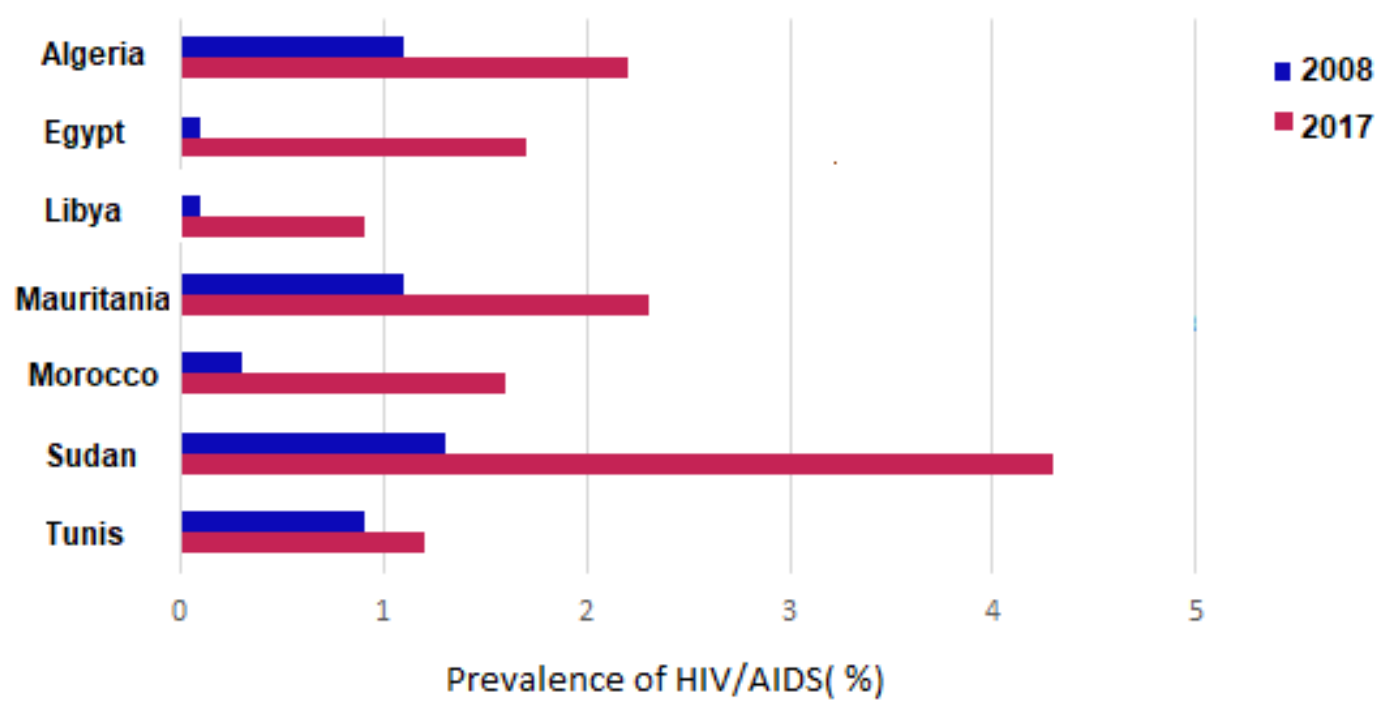

Figure 2

The prevalence of HIV/AIDS in Northern African countries in 2008 and 2017 


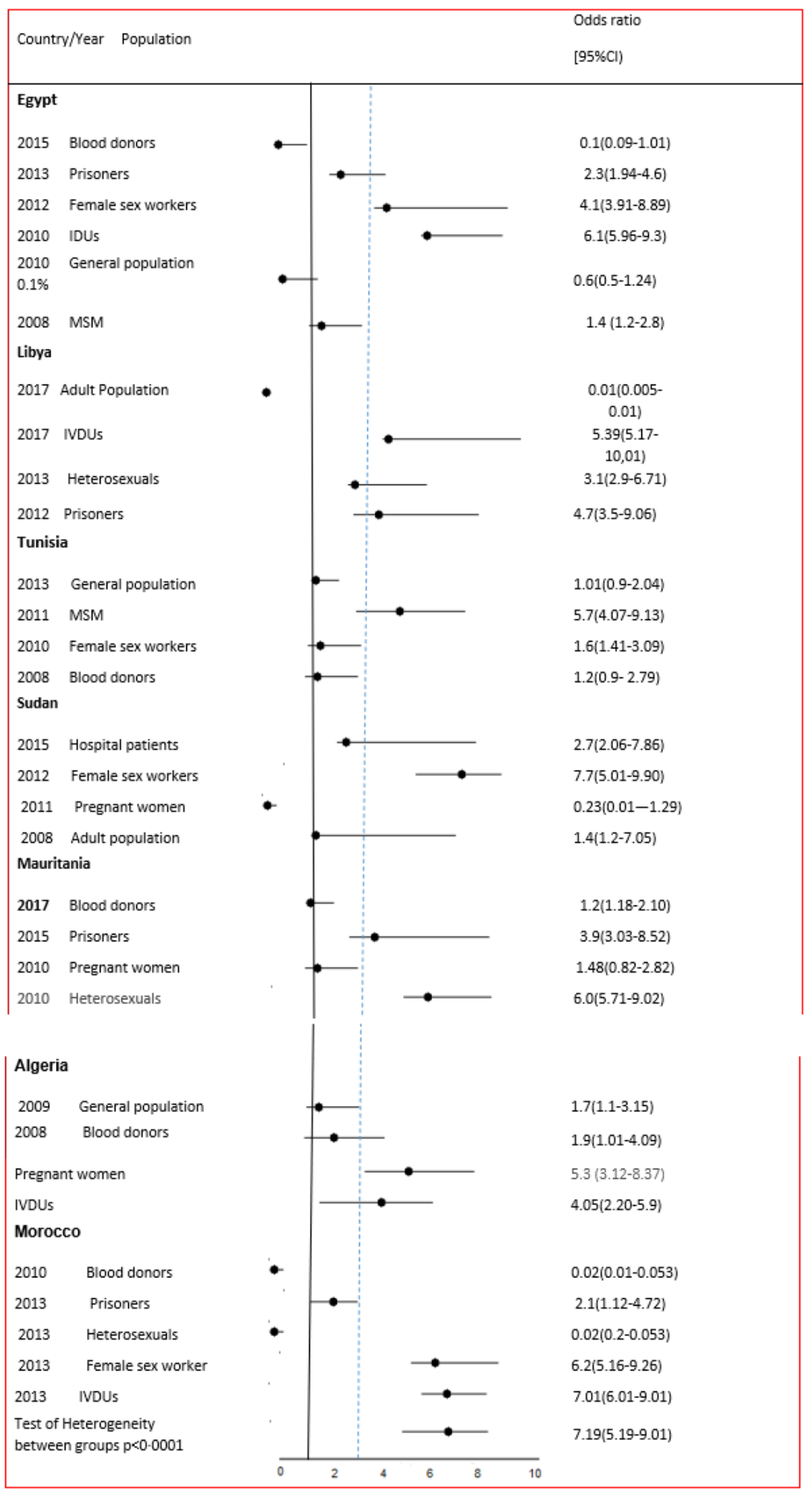

\section{Figure 3}

Forest plot of the seroprevalence of HIV/AIDS among different populations in Northern Africa 2008-2017 


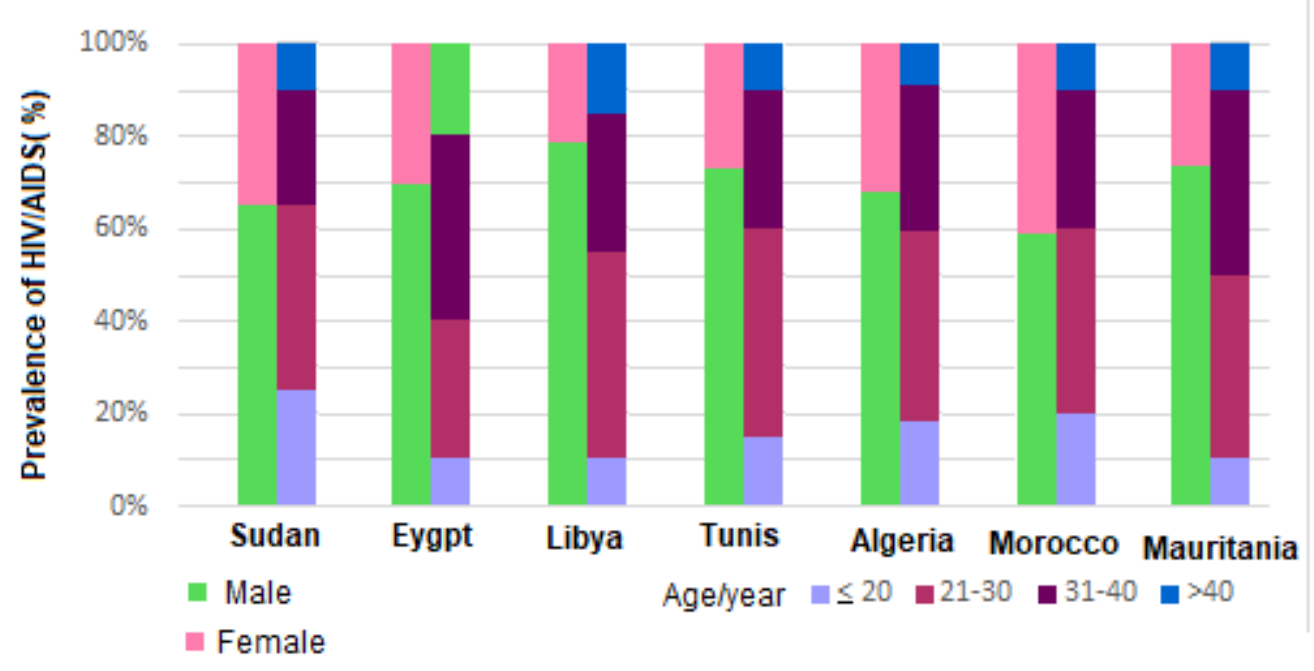

Figure 4

Gender and Age specific distribution of new HIV/AIDS patients reported in Northern African countries from 2008 to 2017. 


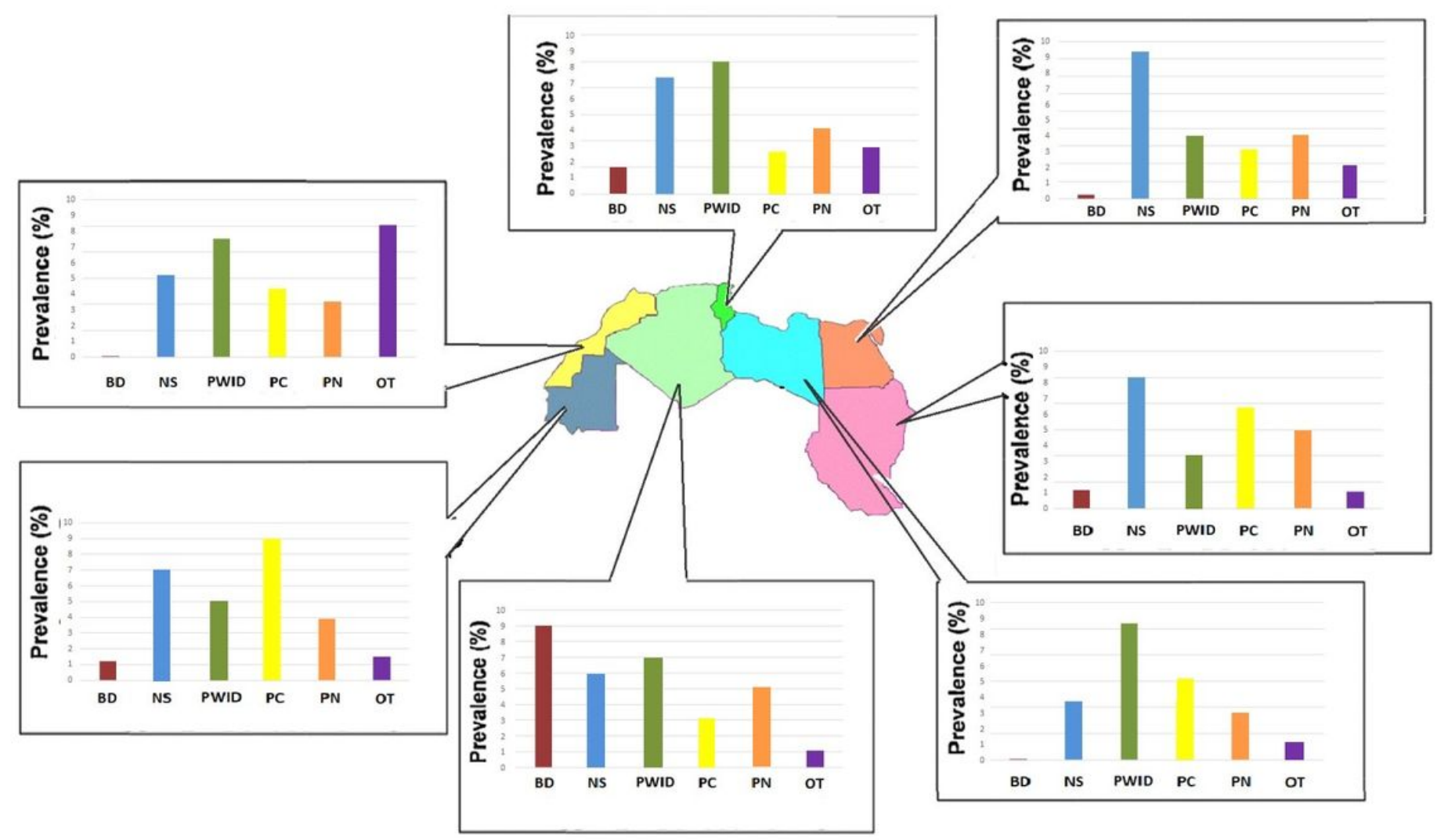

Figure 5

The prevalence of HIV/AIDS among different population groups within the North African countries including; Blood donors[BD], Nosocomial acquired infection [NS], People with injecting drug users PWID , Sexual-Promiscuity[PC] , Prisioners[PN] , others[OT]. 


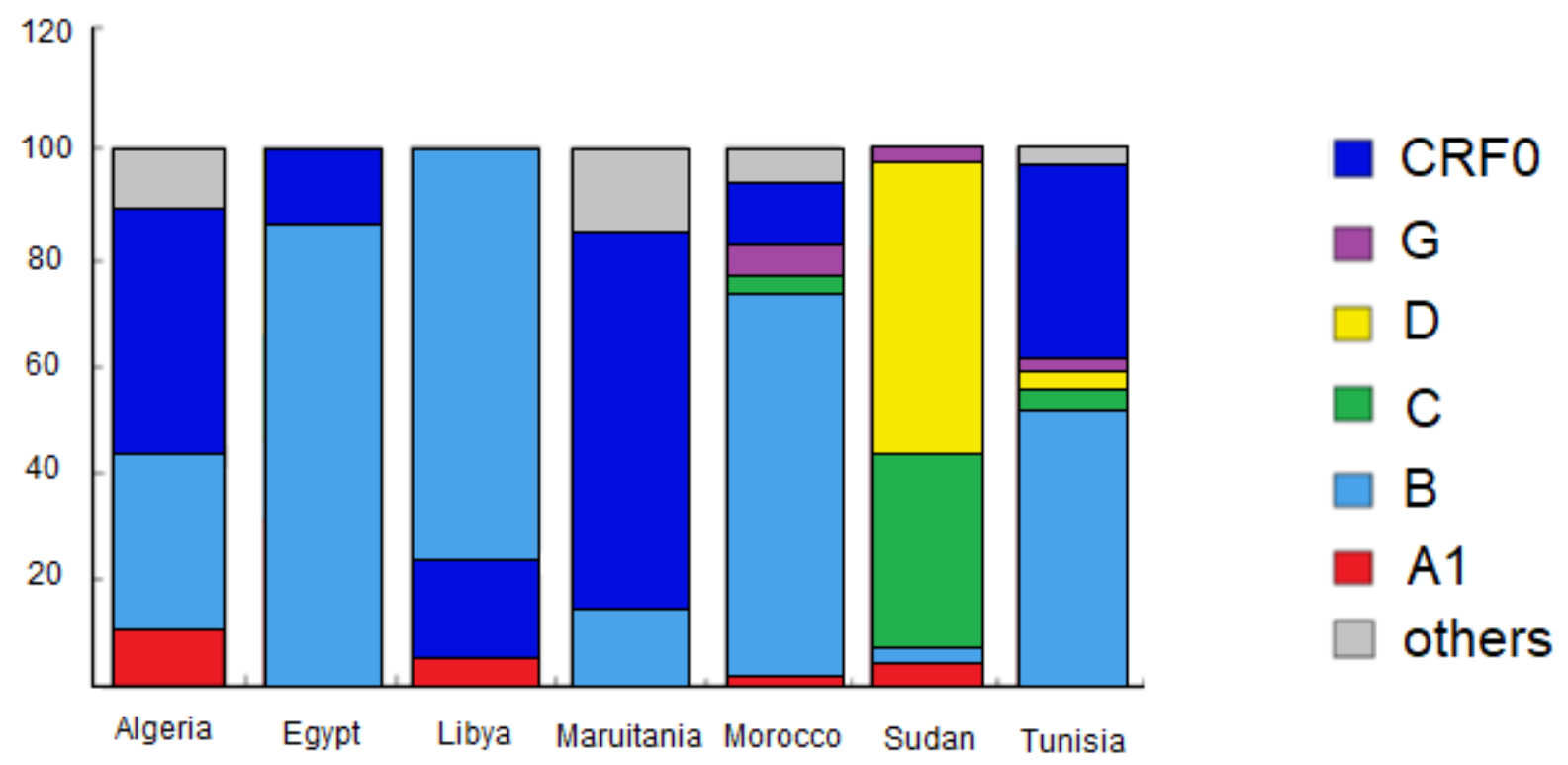

Figure 6

Distribution of HIV genotypes in North African Countries 

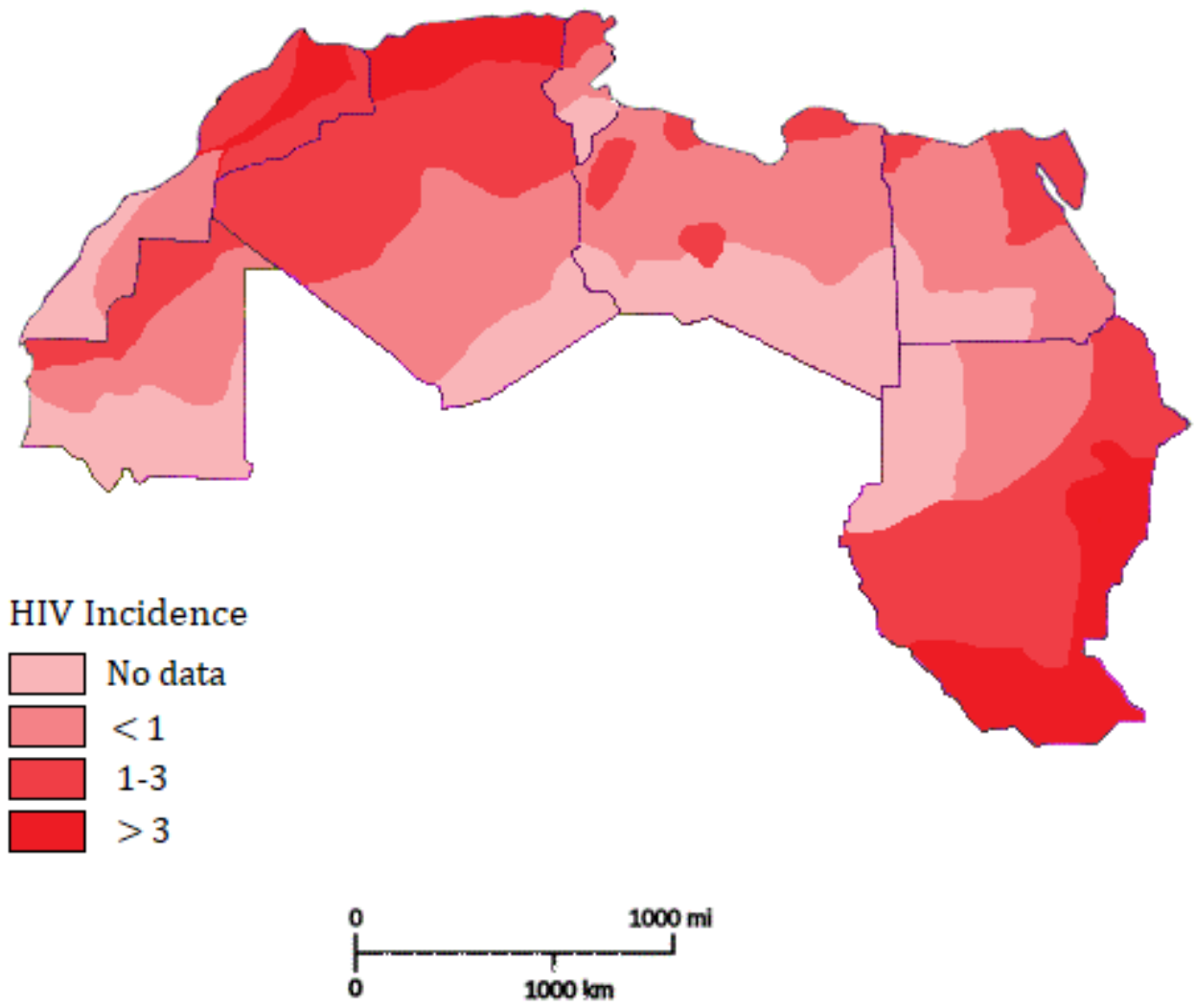

Figure 7

Geographic variation of the incidence of HIV/AIDS in Northern African countries from 2008 to 2017 

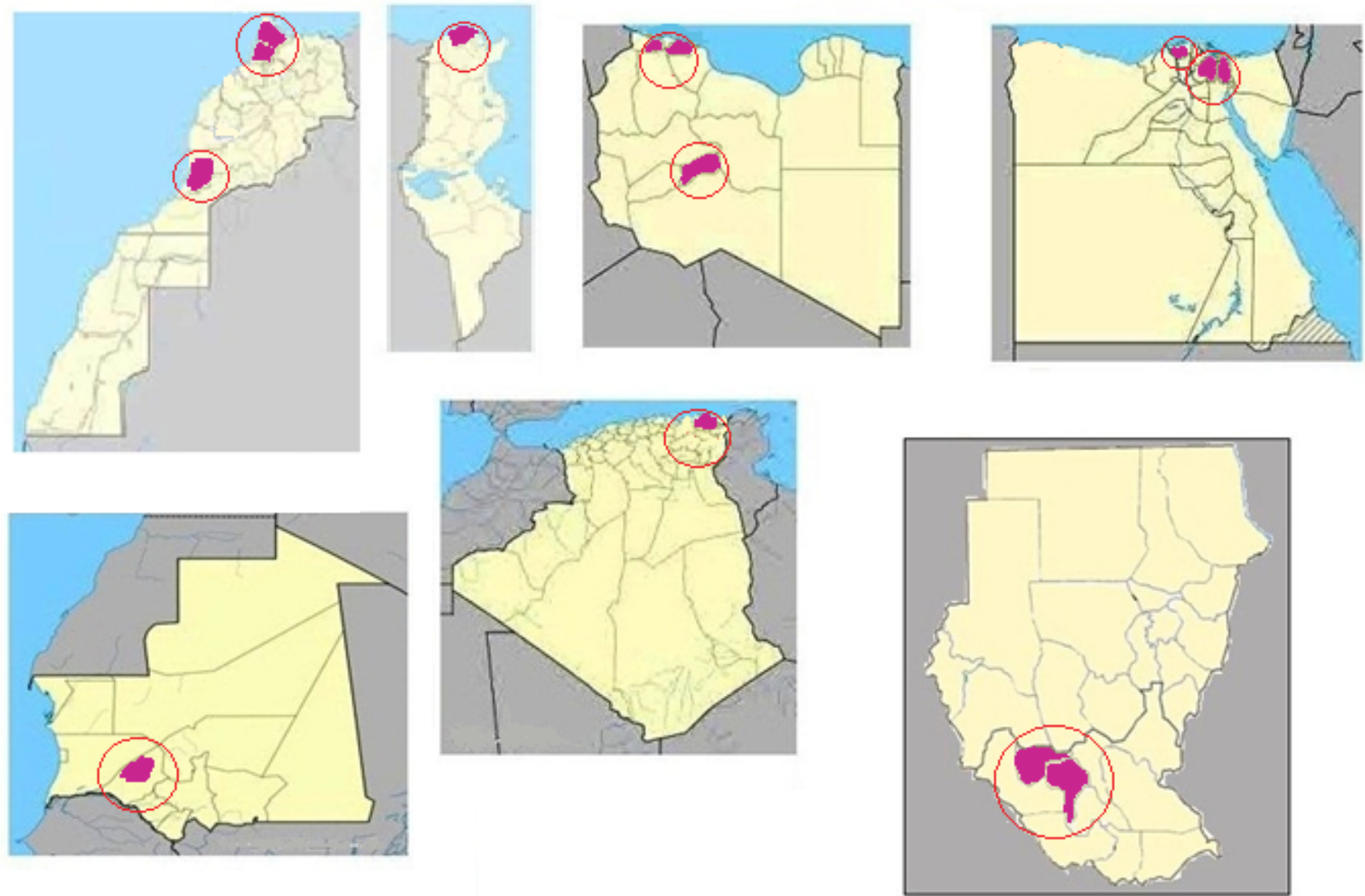

Figure 8

Spatiotemporal clusters of HIV/AIDS in Northern African countries, 2008-2017

\section{Supplementary Files}

This is a list of supplementary files associated with this preprint. Click to download.

- ASupplementryHIVinNorthAfrica.docx 